M. Stockschläder ${ }^{1} \cdot$ M. Montemurro ${ }^{2} \cdot$ T. Kiefer $^{2} \cdot$ G. Dölken ${ }^{2}$

${ }^{1}$ Heinrich-Heine-Universität, Düsseldorf

${ }^{2}$ Ernst-Moritz-Arndt-Universität, Greifswald

\title{
Atemwegsinfektionen bei immunsupprimierten Personen
}

\section{Zusammenfassung}

Pulmonale Infektionen bei immunsupprimierten Patienten stellen auch heute noch eine diagnostische und therapeutische Herausforderung dar. Neue Methoden zur Früherkennung von Pilz- und Virusinfektionen geben Anlass zu der Hoffnung, dass durch eine frühzeitige gezielte Therapie die zum Teil hohe Mortalität gesenkt werden kann. Die Entwicklung neuer Medikamente verspricht eine höhere Effektivität bei geringerer Nebenwirkungsrate. Ein erfolgreiches Management erfordert die interdisziplinäre Zusammenarbeit von Internisten, Infektiologen, Radiologen und Chirurgen.

\section{Schlüsselwörter}

Pulmonale Infektionen . Blutstammzelltransplantation - Allogen . Autolog ulmonale Veränderungen finden sich häufig bei immunsupprimierten Patienten und können durch die Grunderkrankung, deren Behandlung, Infektionen, Tumoren oder Kombinationen dieser Ursachen bedingt sein. Infektiöse Lungenveränderungen müssen abgegrenzt werden von nichtinfektiösen Ursachen wie Lungenödem, diffuser alveolärer Hämorrhagie, Fibrosierung, Hypersensitivitätsreaktion, Alveolarproteinose, Bronchiolitis obliterans und ARDS („adult respiratory distress syndrome“). Die Dauer, Ursache und Intensität der Immunsuppression bestimmen das Muster der Infektionen. Defekte Hautund Schleimhautbarrieren des Patienten durch intensive Chemotherapie oder Bestrahlung prädisponieren zum Eindringen von pathogenen Keimen. Die Neutropenie stellt einen gesicherten Risikofaktor für bakterielle und bei längerer Dauer opportunistische Infektionen dar. Störungen der humoralen Immunität prädisponieren $\mathrm{zu}$ Infektionen mit Streptokokken und bekapselten Bakterien (Haemophilus influenzae, Neisseria meningitidis, Pseudomonas aeruginosa), Störungen der zellulären Immunität zu Infektionen mit Viren, Protozoen wie Toxoplasma gondii, Pilzen, Bakterien oder Helminthen. Eine Spender-gegenWirt-Reaktion („graft versus host disease" $=$ GvHD) oder immunsuppressive Therapie erhöhen ebenfalls das Risiko für pulmonale Infektionen [1].

Diese Arbeit stellt eine Übersicht zu einem Thema dar, das wegen der Hete- rogenität der Formen der Immunsuppression an dieser Stelle nicht in seiner ganzen Breite behandelt werden kann und somit eine fokussierende Beschränkung erfordert. Der inhaltliche Schwerpunkt liegt deshalb auf transplantierten Patienten, jedoch werden auch wichtige Aspekte bei HIV-infizierten Patienten dargestellt. Für die Behandlung einiger Infektionen liegen nicht für jedes Patientenkollektiv Studien vor. Eine Übertragung der Ergebnisse zwischen verschiedenen Patientenkollektiven ist jedoch wegen der unterschiedlichen Form und Dauer der Immunsuppression nicht unproblematisch. Im Folgenden werden prinzipielle Aspekte der Diagnostik und Therapie infektiöser pulmonaler Erkrankungen beschrieben. Auf spezifische diagnostische und therapeutische Modalitäten wird in den Abschnitten zu bakteriellen, viralen und Pilzinfektionen gesondert eingegangen.

Leitsymptome pulmonaler Infektionen sind Fieber, Husten und Dyspnoe, die jedoch auch bei ausgeprägten infektiösen Lungenveränderungen fehlen können. Fieber bei immunsupprimierten Patienten bedarf einer sofortigen

\footnotetext{
(C) Springer-Verlag 2003

M. Stockschläder

Institut für Hämostaseologie und

Transfusionsmedizin, Heinrich-Heine-

Universität, Moorenstraße 5, 40225 Düsseldorf,

E-Mail: marcus.stockschlaeder@uni-

duesseldorf.de
} 
Bundesgesundheitsbl - Gesundheitsforsch Gesundheitsschutz 2003 -46:25-37

DOI 10.1007/s00103-002-0536-7

\section{Stockschläder $\cdot$ M. Montemurro \\ T. Kiefer · G. Dölken}

\section{Pulmonary infections in}

immunocompromised patients

\section{Abstract \\ Pulmonary infections in immunocompro- mised patients remain a diagnostic and therapeutic challenge. New methods for the early detection of fungal and viral diseases might allow an immediate and specific therapy, thereby lowering the high mortality associated with such infections. The develop- ment of new drugs will hopefully lead to more effective treatment while decreasing the incidence of adverse effects. Interdiscipli- nary team work between internal medicine, radiology, surgery, microbiology, and virology is essential for the successful management of these patients.}

\section{Keywords}

Pulmonary infection .

Blood stem cell transplantation · Allogeneic . Autologous

\section{Leitthema: Atemwegserkrankungen bei Kindern und Erwachsenen}

Evaluation. Durch die klinische Untersuchung wird jedoch nur in ca. 30\% der Fälle ein Fokus gefunden [2], wobei pulmonale Infektionen die häufigste Ursache darstellen. Afebrile Infektionen sind möglich. Tritt trotz des Einsatzes von Breitspektrumantibiotika Fieber auf, ist in $40 \%$ der Fälle mit Pilzinfektionen zu rechnen (s. auch den Beitrag von R. Rüchel in dieser Ausgabe). Weitere Ursachen sind bakterielle Infektionen in ca. $10 \%$, Infektionen durch Toxoplasma gondii in ca. $5 \%$, virale Infektionen in ca. $5 \%$ und bei Patienten nach allogener BSZT eine GvHD in ca. $10 \%$. In ca. $25 \%$ der Fälle lässt sich die Ursache nicht genau definieren [3]. Auch wenn pulmonale Infektionen durch eine antibiotische und antimykotische Prophylaxe nicht verhindert werden können, reduzieren diese Maßnahmen erwiesenermaßen die ansonsten hohe Mortalität. Die Resistenzentwicklung bei verschiedenen Erregerarten ist jedoch ein zunehmendes Problem.

\section{„Die Diagnostik pulmonaler Infektionen stellt eine besondere Herausforderung dar."}

Die Diagnostik pulmonaler Infektionen stellt eine ganz besondere Herausforderung dar. Nicht selten sind therapeutische Maßnahmen erforderlich, bevor die Diagnostik abgeschlossen ist bzw. deren Ergebnisse vorliegen. Serologische Untersuchungen sind nur in Einzelfällen hilfreich. Blutkulturen sollten immer angefertigt werden. Hochrisikopatienten erfordern eine regelmäßige Überwachung mittels Polymerasekettenreaktion (PCR) auf Zytomegalievirus (CMV). Auch bei der Toxoplasmose kann eine PCR-Analyse des Blutes oder des Bronchiallavageats diagnostische Bedeutung erlangen [4]. Die Sputumdiagnostik ist bei Nachweis von Pneumocystis carinii und Mycobacterium tuberculosis, bei allogen transplantierten Patienten auch von Aspergillus wegweisend. Beim Nachweis säurefester Stäbchen sollte über Kultur und DNA-Analyse eine exakte Differenzierung der Mykobakterien erfolgen. Die Röntgenuntersuchung des Thorax kann wertvolle Hinweise geben, stellt jedoch nicht jede Infektion in der Frühphase oder der Neutropenie dar.

Auch bei fehlenden radiologischen Hinweisen einer pulmonalen Infektion sollten routinemäßig weiterführende Untersuchungen angeschlossen werden. Rundherde in der Lungenperipherie finden sich häufig bei Pilzinfektionen. Eine gleichförmige, bilaterale, perihilär betonte und interstitielle Zeichnungsvermehrung, die später mit kleinfleckigen Verschattungen einhergeht, kann typisch für die Pneumocystis-cariniiPneumonie (PCP) sein. Bei CMV-Infektionen findet man häufig eine Kombinationen von milchglasartiger, interstitieller Verschattung mit später disseminierten fleckförmigen Knötchen, wobei die Unter- und Mittelfelder betont betroffen sind [5].

Die Computertomographie des Thorax ist sehr aussagekräftig und sollte so früh wie möglich erfolgen. $\mathrm{Zu}$ bevorzugen ist die hochauflösende Technik („high resolution-CT“=HRCT). Bei normalen HRCT ist eine manifeste pulmonale Infektion unwahrscheinlich [6]. Die perkutane Punktion von Herden in der Lungenperipherie kann CT-gestützt oder unter sonographischer Kontrolle erfolgen. Hierdurch lässt sich sehr häufig der auslösende Keim erfassen. Die Komplikationsrate beträgt ca. 1\% [7].

Die fiberoptische Bronchoskopie (FOB) mit bronchoalveolärer Lavage (BAL) stellt eine der wichtigsten diagnostischen Maßnahmen zur Abklärung pulmonaler Infiltrate febriler neutropener Patienten dar. Die Ergebnisse dieser Untersuchung sind jedoch in hohem Maße abhängig von der Probenaufarbeitung, die im Voraus geplant und im Labor angekündigt werden muss. Die gezielte Sondierung computertomographisch ausgewählter Segmente verbessert die Ergebnisse [8]. Die Komplikationsrate wird mit $2-20 \%$ angegeben. $\mathrm{Zu}$ meist handelt es sich hierbei um postinterventionelles Fieber. Blutungen treten selbst bei thrombozytopenischen Patienten selten auf. Zur Vermeidung einer respiratorischen Dekompensation wird empfohlen, dass auch nicht intubierte hypoxische Patienten unter kontinuierlich positivem Atemwegsdruck bronchoskopiert werden [9]. Alternativ erfolgt die Bronchoskopie unter Sauerstoffzufuhr und Kontrolle der Sauerstoffsättigung. Durch die BAL kann in $30-70 \%$ der Fälle ein Erreger isoliert werden. Darüber hinaus konnte nachgewiesen werden, dass ca. 50\% der ermittelten Keime resistent gegen die aktuell applizierte Therapie waren [10]. Ein 
Screening mittels FOB+BAL ist klinisch nicht sinnvoll [11].

Die transbronchiale (TBB), videothorakoskopische oder offene Lungenbiopsie (OLB) sollte dann zum Einsatz kommen, wenn andere diagnostische Verfahren oder empirische Therapie versagt haben oder nicht-infektiologische Ursachen, wie z. B. Tumor, Fibrose oder interstitielle Lungenerkrankungen, vermutet werden. In ca. $3 \%$ der Interventionen ist mit einer relevanten Blutung $\mathrm{zu}$ rechnen. Bei der TBB beträgt die Letalität weniger als $1 \%$. Die OLB besitzt die höchste Sensitivität und Spezifität aller bisher diskutierten Methoden und gilt als sichere Untersuchung. Noch nicht endgültig geklärt sind die Indikation zur OLB und die Frage, ob das Gesamtüberleben trotz der exzellenten diagnostischen Aussagekraft verbessert wird [12]. Die TBB oder OLB sollte jedoch stets erwogen werden, wenn die BAL diagnostisch nicht wegweisend war [13].

\section{Infektionsrisiken nach allogener BSZT}

Nach allogener BSZT werden das Infektionsrisiko und der Schweregrad der Infektion mit den möglichen Komplikationen ganz wesentlich mitbestimmt durch das Stadium der Grunderkrankung, die Vorbehandlung, die Transplantationsmodalität (z. B. Grad der HLA-Identität zwischen Spender und Empfänger, TZell-Depletion), die Rekonstitution der Hämatopoese und das Auftreten einer GvHD. Die Zeit nach der allogenen BSZT wird in 3 Phasen mit z. T. typischen Infektionen eingeteilt.

\section{Frühe Posttransplantationsphase}

Aufgrund der hochdosierten Chemo-/ Strahlentherapie kommt es in den ersten 30 Tagen nach der Transplantation zu einer Ablation der Hämatopoese mit schwerer peripherer Zytopenie. Der immunologische Defekt ist vorwiegend in der Neutropenie begründet. Die generalisierte Mukositis bedeutet multiple Eintrittspforten für Erreger. In dieser Phase werden häufig diffuse beidseitige Lungeninfiltrate aufgrund einer toxischen Lungenschädigung durch Chemotherapie und Strahlentherapie in zeitlicher Assoziation mit Fieber beobachtet. Differenzialdiagnostisch sind pulmonale Blutungen bei erniedrigten Thrombozy-
Übersicht 1

Nichtinfektiöse Ursachen pulmonaler Erkrankungen bei immunsupprimierten

Patienten

- Chemotherapie bedingte Toxizität (z. B. Cytosinarabinosid, Busulfan, Bleomycin),

- Strahlenpneumonitis (Beziehung zu Strahlenfeld, bestrahltem Lungenvolumen und Dosis),

- pulmonale Blutungen,

- pulmonale Metastasierung (Progress der Grunderkrankung!),

- Lungenembolien (blande verlaufend),

- kardiogenes Lungenödem,

- „adult respiratory distress syndrom“ (ARDS)

- hepatische „veno-occlusie disease" (VOD),

- transfusion related acute lung injury

tenzahlen, pulmonale Stauung infolge kardiotoxischer Chemotherapie, hepatische VOD („veno-occlusive disease“), „capillary leak syndrome“ und ARDS zu erwägen (Übersicht 1). Häufigste infektiöse Erreger von Pneumonien in dieser Phase sind Bakterien (90\%) und Pilze.

\section{Mittlere Posttransplantationsphase}

Von Tag 30 bis Tag 100 steigt die Rate der infektiösen Komplikationen aufgrund der abgeschwächten zellulären Immunität, die B- und T-Zellen betrifft, stark an. Die akute GvHD verstärkt und verlängert die bereits bestehende Immunsuppression.

\section{Späte Posttransplantationsphase}

Diese Phase (>100 Tage) ist geprägt von einer kombinierten Störung der zellulären und humoralen Immunität, der Beeinträchtigung des retikuloendothelialen Systems und dem Auftreten der so genannten chronischen GvHD.

\section{Bakterielle Infektionen}

\section{Inzidenz}

Pulmonale Infiltrate sind bei Patienten nach Organ- oder Knochenmarktransplantation in der frühen Posttransplantationsphase am häufigsten durch Bak- terien verursacht. Dabei schwankt das Vorkommen bakteriell bedingter Infiltrate zwischen 2 und 50\% $[14,15,16,17$, 18]. In der frühen Periode nach Organtransplantation werden vor allem gramnegative Erreger wie Klebsiellen, Pseudomonaden (gehäuft nach Lungentransplantation), E. coli, Proteus, Serratia und Enterobacter gefunden. Später herrschen ambulant erworbene Erreger vor, zu denen Streptococcus pneumoniae und Haemophilus influenzae gerechnet werden. Ein Nachweis von Streptococcus pneumoniae in der Blutkultur ist fast immer mit einer Pneumonie vergesellschaftet [19]. Von einer spanischen Arbeitsgruppe wurde Streptococcus pneumoniae bei 5\% aller Bakteriämien neutropenischer Patienten nachgewiesen. Bei $71 \%$ dieser Patienten kam es $z u$ Pneumonien, von denen nahezu 50\% resistent gegenüber Penicillin waren.

In der späten Posttransplantationsphase werden neben Streptokokken besonders häufig Pneumonien durch Staphylococcus aureus verursacht. Nach der BSZT haben Infektionen mit grampositiven Erregern zwar deutlich zugenommen (bis zu 40\%), gramnegative Bakterien bleiben jedoch die häufigsten Erreger. Nierentransplantierte Patienten haben ein besonders hohes Risiko, eine Legionellenpneumonie $\mathrm{zu}$ entwickeln. AIDS-Patienten erleiden gehäuft klinisch atypische Infektionen mit Pseudomonaden und Streptokokken. Auch Infektionen mit Mycobacterium tuberculosis sollten bei AIDS-Patienten stets in die differenzialdiagnostischen Überlegungen einbezogen werden. Auch nach Herz- und Nierentransplantation kommt es gehäuft zu Tuberkulose (bis zu 1\%), entweder als Reaktivierung oder als eine frische Infektion über den Spender. Die Erkrankung tritt meistens später als ein Jahr nach Transplantation auf. Atypische, ubiquitär vorhandene Mykobakterien sind nur sehr selten der Grund für pulmonale Infiltrate. Patienten mit einem Defekt der zellulären Immunität sind in besonderem Maße gefährdet [20]. Die Therapiedauer sollte ausgedehnt werden, ist aber nicht einheitlich definiert.

\section{Diagnostik}

Die Diagnose einer bakteriellen Pneumonie wird in der Regel mittels Bildgebung gestellt. Progredienz, radiologische Cha- 
rakteristika und die Phase der Immunsuppression, in der pulmonale Infiltrate auftreten, können Hinweise auf den Erreger geben. Die rasche Zunahme eines pulmonalen Infiltrates spricht am ehesten für eine bakterielle Genese. Pneumonien, die durch Legionellen und Mykobakterien verursacht werden, zeigen mitunter auch einen subakuten Verlauf. In der neutropenen Phase nach allogener BSZT sind die Symptome häufig nur gering ausgeprägt. Fieber tritt fast regelmäßig auf. Husten und eitriges Sputum finden sich in einer Häufigkeit von 70\% bzw. 8\% [21]. Die Spezifität der Bildgebung ist gering. In der neutropenen Phase schließt ein unauffälliges Röntgenbild eine Pneumonie nicht aus. Ein HRCT zeigt in dieser Situation eine deutlich höhere Sensitivität. In Abhängigkeit von der antibiotischen Prophylaxe können differenzialdiagnostisch bestimmte Keime weitgehend ausgeschlossen werden: unter Trimethoprim/Sulfamethoxazol sind Pneumocystis carinii-, unter Fluorochinolonen oder Makroliden Legionellen- und unter Penicillin V Streptokokkeninfektionen unwahrscheinlich.

\section{Prophylaxe}

Eine ausgeprägte und lang anhaltende Neutropenie ist häufig mit bakteriellen Komplikationen verbunden, die mit einer antibiotischen Prophylaxe verhindert werden können. Der Vorteil der Prophylaxe muss abgewogen werden gegen die potenziellen Nachteile (z. B. allergische Reaktionen, Toxizität, Entwicklung resistenter Keime, Pilzüberwucherung). Zur Prophylaxe sind neben nicht resorbierbaren („selektive Darmdekontamination") auch resorbierbare Antibiotika eingesetzt worden. Zwei Regime haben sich etabliert: Trimethoprim/Sulfamethoxazol (TMP-SMZ) und Chinolone. Randomisierte Studien belegen eine Verminderung infektiöser Komplikationen nach prophylaktischer Gabe von TMP-SMZ. Außerdem besitzt TMP-SMZ eine nachgewiesene Wirksamkeit in der Prophylaxe von Pneumocystis-cariniiInfektionen. Nebenwirkungen sind eine Myelosuppression mit einer protrahierten Neutropenie und der Kolonisation mit Pilzen [22]. TMP-SMZ ist unwirksam gegenüber Pseudomonas aeruginosa. Orale Chinolone verhindern im Vergleich zu TMP-SMZ fieberhafte Episoden infektiöser Genese effektiver [23], jedoch wird hier zunehmend die Entwicklung resistenter Erreger beschrieben [24]. Trotz der bewiesenen Effektivität kann der prophylaktische Einsatz von TMP-SMZ oder Chinolonen bei neutropenen Patienten wegen der Entwicklung resistenter Keime nicht uneingeschränkt empfohlen werden. Es wird eine Einteilung der Patienten in 3 verschiedene Risikogruppen (Niedrig-, Standard- und Hochrisiko) empfohlen. Die dazu erschienenen und in regelmäßigen Abständen aktualisierten Leitlinien der Deutschen Gesellschaft für Hämatologie und Onkologie sind im Internet abrufbar (www.dgho-infektionen.de).

Bei HIV-Patienten wird eine Prophylaxe gegen atypische Mykobakterien bei einem Abfall der CD4-positiven Zellen unter 50/ $\mu$ l angeraten. Mittel der Wahl sind hierfür Azithromycin bzw. Clarithromycin. Falls der Tuberkulinhauttest positiv ausfällt und der HIV-Patient noch nie zuvor gegen Tuberkulose behandelt oder eine Prophylaxe erhalten hat, sollte nach Ausschluss einer aktiven Tuberkulose eine Prophylaxe mit Isoniazid täglich oder jeden 2. Tag für 9 Monate oder alternativ mit Rifampicin in Kombination mit Pyrazinamid täglich für 2 Monate erfolgen. Ebenso sollte verfahren werden, wenn ein HIV-Patient über eine Tuberkuloseexposition berichtet, auch wenn der Tuberkulinhauttest negativ ausfällt. HIV-Patienten sollten gegen Pneumokokken geimpft werden, sobald die Anzahl der CD4-positiven Zellen über $200 / \mu \mathrm{l}$ im peripheren Blut liegt [25]. Neben den hier aufgeführten Möglichkeiten der Chemoprophylaxe muss der Patient über Verhaltensregeln informiert werden, um eine Exposition gegenüber Infektionen $\mathrm{zu}$ vermeiden.

\section{Therapie}

Die Therapie entspricht der bei Fieber unklarer Genese. Patienten mit akuter Leukämie, die in der Neutropenie Fieber und pulmonale Infiltrate entwickeln und deren Neutropenie länger als 10 Tage anhält, sollten in der Initialtherapie ein Acylaminopenicillin (in Kombination mit einem $\beta$-Lactamase-Inhibitor) oder ein Cephalosporin der 3. Generation erhalten, evtl. in Kombination mit einem Aminoglykosid oder Amphotericin B. Die zusätzliche Gabe eines Aminoglykosids wird von der lokalen
Resistenzlage und dem Keimspektrum abhängig gemacht. Mindestens gleichwertig ist eine empirische Therapie mit einem Carbapenem [26, 27, 28, 29]. Die Zugabe eines Aminoglykosids in der Neutropenie zeigte keinen Vorteil [30,31, 32]. Die antibiotische Therapie sollte nach Erhalt der mikrobiologischen Testergebnisse ggf. modifiziert werden. Zur Relevanz von Testergebnissen bezüglich der Ätiologie eines Lungeninfiltrats s. Tabelle 1. Neben dem in vitro ausgetesteten Resistenzspektrum sind auch die Penetrationsfähigkeit der Substanz in das Lungengewebe, die zu erwartende Toxizität, individuelle Kontraindikationen (wie z. B. bekannte Allergien), klinikinterne Resistenzentwicklungen und nicht zuletzt auch pharmaökonomische Gesichtspunkte zu berücksichtigen.

\section{Virusinfektionen}

\section{Inzidenz}

Im Vergleich zu Patienten unter konventioneller Chemotherapie oder Hochdosis-Chemotherapie mit autologer BSZT sind die Patienten nach allogener BSZT für pulmonale Virusinfektionen besonders empfänglich. Dies gilt auch für Patienten unter immunsuppressiver Therapie nach Organtransplantation und für AIDS-Patienten. Durch den prophylaktischen Einsatz von Acyclovir sind virale Pneumonien durch Herpes-simplex-Virus (HSV) in der frühen Posttransplantationsphase (Tag 1-30) selten geworden. Durch intensive Kontrolluntersuchungen mit verbesserten Nachweismethoden werden jedoch zunehmend andere Viren als mögliche Erreger von Infektionen des oberen und unteren Respirationstraktes nachgewiesen: „respiratory syncytial virus“ (RSV), Rhinoviren, Influenzaviren Typ A, Parainfluenzaviren Typ 1 und 3 sowie Adenoviren [33]. RSV-Infektionen beginnen häufig im oberen Respirationstrakt als Sinusitis mit Fieber. Bei immunsupprimierten $\mathrm{Pa}$ tienten kann sich im weiteren Verlauf eine Pneumonie entwickeln. So konnte bei 26 von 336 allogen transplantierten Patienten (6\%) RSV nachgewiesen werden; 5 Patienten $(19,2 \%)$ verstarben an den Folgen dieser Infektion [34]. Parainfluenzavirusinfektionen (Rhinitis, Pharyngitis, Pneumonie) konnten bei 253 von 3.577 transplantierten Patienten $(7,1 \%)$ nachgewiesen werden. In der 
Tabelle 1

Relevanz mikrobiologischer Befunde für pulmonale Infiltrate

\begin{tabular}{|c|c|c|c|}
\hline Nachweis von & Untersuchtes Material & Bewertung & Bemerkungen \\
\hline Pneumocystis carinii & Sputum bzw. BAL & $\begin{array}{l}\text { Hohe Bedeutung für die Ätiologie } \\
\text { des Lungeninfiltrats }\end{array}$ & \\
\hline \multicolumn{4}{|l|}{ Pneumokokken } \\
\hline \multicolumn{4}{|l|}{ Mykobakterium tuberculosis } \\
\hline \multicolumn{4}{|l|}{ Aspergillus spp. } \\
\hline Pneumokokken & Blut & & \\
\hline \multicolumn{4}{|l|}{ Vergrünende Streptokokken } \\
\hline \multicolumn{4}{|l|}{ Gramnegative Aerobier } \\
\hline Jeder Keimnachweis & Biopsiematerial & & \\
\hline Legionellen-Ag/Pneumokokken-Ag & Urin & & \\
\hline Candida spp. & BAL oder Blut & $\begin{array}{l}\text { Möglicherweise von Bedeutung } \\
\text { für die Ätiologie des Lungeninfiltrats }\end{array}$ & $\begin{array}{l}\text { Es kann trotz eines Candida- } \\
\text { nachweises eine Infektion } \\
\text { durch Aspergillus spp. vorliegen }\end{array}$ \\
\hline Aspergillus spp. & Nasen- oder Rachenabstrich & & \\
\hline $\begin{array}{l}\text { Staphylococcus aureus, Legionellen, } \\
\text { Chlamydien, Zytomegalieviren, Herpesviren }\end{array}$ & BAL & & \\
\hline Vergrünende Streptokokken & Abstrich, Sputum, BAL & & \\
\hline Enterokokken & Abstrich, Sputum, BAL, Blut & $\begin{array}{l}\text { Geringe Bedeutung für die } \\
\text { Ätiologie des Lungeninfiltrats }\end{array}$ & \\
\hline $\begin{array}{l}\text { Koagulasenegative Staphylokokken, } \\
\text { Corynebakterium spp. }\end{array}$ & Jedes Material & & \\
\hline Candida spp. & Abstrich, Sputum & & \\
\hline Jeglicher Keimnachweis & Stuhl- oder Urinkulturen & & \\
\hline
\end{tabular}

BAL bronchoalveoläre Lavage.

Mehrzahl der Fälle (78\%) war die Infektion vor der Transplantation erworben worden [35]. 55 der 253 Patienten (24\%) erkrankten an einer Pneumonie. Bei $53 \%$ konnten in der BAL jedoch weitere pathogene Keime isoliert werden. Adenoviren können im Rachenspülwasser bei $6-21 \%$ der transplantierten Patienten nachgewiesen werden; die Erkrankungsrate liegt bei 1-6\% der Patienten. Tödliche Komplikationen wie Pneumonien werden bei 1-6\% der Infizierten beobachtet [36]. Adenovirusinfektionen werden bei Kindern häufiger und früher nach der Transplantation beobachtet als bei Erwachsenen.

Mit einer CMV-Infektion ist bei HIV-Patienten bei weniger als $50 / \mu \mathrm{l}$ CD4-Zellen und nach Transplantation in 60-70\% der Fälle zu rechnen, wenn der Spender oder der Empfänger CMV-seropositiv ist. In der mittleren Posttransplantationsphase (Tag 30-100) war das in der Vergangenheit die Ursache hoher CMV-Erkrankungsraten (20-30\%) und CMV-assoziierter Mortalität [37].
Aufgrund einer frühzeitig eingeleiteten antiviralen Therapie bei Vorliegen einer CMV-Infektion erleiden heute nur noch 5-15\% der allogen transplantierten Patienten bei CMV-seropositiven Empfänger/Spender-Kombinationen eine CMV-Erkrankung inklusive CMV-Pneumonie [38]. Etwa die Hälfte der interstitiellen Pneumonien nach allogener BSZT wird durch CMV verursacht. Andere Viren wie HSV, RSV und VZV werden in nur etwa 10\% der Fälle als ursächliche Erreger gefunden. So genannte idiopathische Pneumonien ohne Erregernachweis gehen meist auf eine nicht diagnostizierte CMV-Infektion zurück. In der mittleren Posttransplantationsphase können aus verschiedenen Körperflüssigkeiten kulturell besonders häufig Adenoviren vom Serotyp 11, 34 und 35 nachgewiesen werden. Beim Nachweis von Adenoviren im Rachenspülwasser und im Urin bei ca. 4-20\% der transplantierten Patienten bleibt es jedoch unklar, wie häufig Pneumonien durch Adenovirusinfektionen hervorgerufen werden [39].
In der späten Posttransplantationsphase (>100 Tage) werden virale Infektionen hauptsächlich durch Herpesviren hervorgerufen: CMV,VZV und EBV. Die seltene viszerale Disseminierung der VZV-Infektion inklusive der VZV-Pneumonie tritt als späte Komplikation bei etwa $1 \%$ der allogen transplantierten $\mathrm{Pa}$ tienten auf und verläuft trotz Therapie mit Aciclovir in etwa 50\% der Fälle tödlich. Risikofaktoren sind eine aktive GvHD und möglicherweise eine vorausgegangene nicht-disseminierte VZV-Infektion. RSV-Infektionen sind in dieser Phase seltener als in den ersten 30 Tagen und verlaufen oft milder [40].

\section{Diagnostik}

Die Diagnose einer HSV-Infektion erfolgt je nach klinischer Manifestation über die Anzüchtung des Virus aus dem Rachenspülwasser, Schleimhaut- oder Hautabstrich, den direkten Antigennachweis (z. B. im Bläscheninhalt) oder den Nachweis der viralen DNA mit der 
PCR. Bei Symptomen des oberen Respirationstraktes und Verdacht auf eine Infektion durch respiratorische Viren werden Rachenspülwasser und Sputum mit einem Antigen-ELISA oder durch Virusisolierung in der Zellkultur untersucht. Bei Symptomen des unteren Respirationstraktes wird zusätzlich Material durch die FOB und BAL gewonnen. Bei Verdacht auf eine Adenovirusinfektion werden zusätzlich Urin, Stuhl und Gewebsproben auf Adenoviren (AntigenELISA, Zellkulturverfahren) untersucht.

Die Diagnostik der CMV-assoziierten Pneumonie ist in Übersicht 2 zusammengefasst. Diffuse Infiltrationen im Röntgenbild des Thorax im Sinne einer interstitiellen Pneumonie, evtl. erhärtet durch eine computertomographische Untersuchung und der Nachweis von CMV in der BAL mithilfe eines Zellkulturverfahrens, sichern die Diagnose. Die CMV-spezifischen Untersuchungsverfahren sind in der Übersicht 3 zusammengefasst.

Das humane Herpesvirus 6 (HHV6) konnte bei Patienten mit CMV-Pneumonie häufig in der BAL nachgewiesen werden. $\mathrm{Ob}$ es sich um ein wichtiges pathogenes Agens, einen Kofaktor der letalen CMV-Pneumonie oder eine Virus-

\section{Übersicht 2}

Diagnostik und Differenzialdiagnose der Cytomegalievirusassoziierten Pneumonie

\section{Verfahren:}

- Röntgen-Thoraxübersicht in zwei Ebenen,

- HR-Computertomographie des Thorax (insbesondere bei negativem RöntgenThorax),

- Bronchoskopie mit bronchoalveolärer Lavage (BAL), Untersuchung auf Viren: CMV, HSV, HHV6, respiratorische Viren, wie z.B. RSV, IV, PIV, Adenoviren durch Anzüchtung, Antigen-ELISA, PCR u.a., auf Bakterien, Pilze, Pneumocystis carinii, Mykobakterien, Toxoplasmose, Legionellen mit den Methoden: Mikroskopie, Immunzytochemie, Kultur und PCR.

Diagnose:

- interstitielle Pneumonie (radiologisch)

- Nachweis von CMV in der BAL mit Hilfe von Zellkulturverfahren
Übersicht 3

CMV-spezifische Untersuchungsverfahren zur Diagnostik und Verlaufskontrolle unter antiviraler Therapie

\section{A. Replikations- oder Antigen- spezifische Teste}

1. „shell vial culture“ (Gleaves et al. 1985),

2. pp65,Antigenämie" (Boeckh et al. 1999).

\section{B. CMV-DNA/RNA-spezifische Teste}

1. Nachweis von CMV-DNA mit StandardPCR-Methoden (Einsele et al. 1991; Einsele et al. 1995)

2. Quantitativer CMV-DNA-Nachweis mit „real-time" quantitativer PCR (Limaye et al.2001; Yun et al.2000),

3. "hybrid capture assay" für CMV-DNA (Hebart et al.2001),

4. "nucleic acid sequence based amplification" (CMV-RNA) (Compton 1991)

reaktivierung ohne pathogene Bedeutung handelt, bleibt zu klären [41].

Bei HIV-infizierten Patienten kommt es auch bei peripheren CD4-Zellen unter 5o/ $\mu$ l nur selten zu einer CMVPneumonie (4-10\%) [42]. Typisch sind diffuse Infiltrate im Thoraxröntgenbild. Zur Diagnostik und vor allem zur Abgrenzung gegen Pneumocysis-carinii-Infektionen sind die Untersuchung des induzierten Sputums, evtl. eine BAL und möglicherweise eine TBB angezeigt. Im Gegensatz zur CMV-Retinitis, -Gastroenteritis und -Enzephalomyelitis ist die CMV-Pneumonie bei HIV-Infizierten selten und verläuft weniger dramatisch als bei allogen transplantierten Patienten.

\section{Prophylaxe}

Alle Patienten sollten vor der Transplantation auf Antikörper gegen HSV getestet werden. Antikörper-negative Patienten sollten über Maßnahmen zur Erniedrigung des Risikos einer Primärinfektion während der Zeit der Immunsuppression, z. B. die Vermeidung des Kontakts mit potenziell infektiösen Sekreten, aufgeklärt werden. Die in der ersten Phase nach allogener Blutstammzelltransplantation nahezu generell ausgeübte Prophylaxe mit Aciclovir (4-mal 200-400 mg/Tag p.o. oder 3-mal 250 mg/ $\mathrm{m}^{2} /$ Tag i.v.), von Tag -7 bis ca. +30 bzw. bis zur hämatologischen Rekonstitution, reduziert die HSV-Reaktivierungsrate innerhalb der ersten 100 Tage um 75\% [43]. Das Risiko einer Resistenzentwicklung unter prophylaktischer Gabe von Aciclovir muss beachtet werden. Aufgrund dieser antiviralen Prophylaxe werden VZV-Infektionen in der frühen Posttransplantationsphase nur noch bei etwa 20\% der Patienten beobachtet [44].

Da die Mortalität der CMV-Pneumonie bei $80-90 \%$ liegt, ist ab Tag 30 nach allogener BSZT eine intensive Überwachung, Diagnostik und Therapie der CMV-Infektionen notwendig. Wichtigster prognostischer Faktor für die CMV-Erkrankung ist der CMV-Serologiestatus von Spender (S) und Empfänger (E) vor der Transplantation. Bei CMV-seronegativen E/S-Kombinationen werden nur CMV-seronegative oder Leukozyten-depletierte Blutprodukte gegeben [45]. Bei seropositiven E/S-Kombinationen $(\mathrm{E}+/ \mathrm{S}-; \mathrm{E}+/ \mathrm{S}+; \mathrm{E}-/ \mathrm{S}+)$ werden hauptsächlich 2 Strategien verfolgt: a) eine „,antivirale Prophylaxe“ mit Ganciclovir beginnend vom Tag der hämatologischen Rekonstitution bis Tag 100 ohne wöchentliche virologische Untersuchungen [46, 47],

b)Frühinterventionstherapie oder „preemptive treatment“, basierend auf einer wöchentlichen Überwachung mit mindestens einer der folgenden Methoden:

- CMV-spezifische PCR möglichst in Kombination mit einem Test auf CMV-pp65-Antigen (Antigenämie) in Leukozyten [78] oder

- Isolierung des Virus aus Urin, Speichel, Blut, BAL mit der „shell vial culture" [49] bzw.

- Isolierung des Virus durch Routinekulturverfahren [50].

Im Fall des CMV-Nachweises erfolgt eine Behandlung mit Ganciclovir (2-mal $5 \mathrm{mg} / \mathrm{kg}$ ) oder Foscarnet (2-mal $60 \mathrm{mg} / \mathrm{kg}$ ). Mithilfe einer quantitativen CMV-PCR können Patienten mit einem hohem Risiko für eine CMV-Pneumonie identifiziert werden [51]. Die Frühinterventionstherapievariante b) wird bevorzugt, da damit die Ganciclovirtherapie auf Patienten mit einer CMV-Infektion und einem hohen Risiko für eine schwere CMV-Erkrankung beschränkt wird. Bei Patienten mit einem besonders hohen Risiko für eine CMV-Infektion und CMV-Erkrankung wird eine „modifi- 
zierte, risikoadaptierte antivirale Prophylaxe" mit Ganciclovir empfohlen [52].

Die Therapiestrategien „universelle Prophylaxe“ und "preemptive treatment" der CMV-Erkrankung gelten auch für Patienten mit iatrogener Immunsuppression nach Organtransplantation. Die Dauer der Frühinterventionstherapie sollte bei Patienten nach Transplantation von soliden Organen oder allogenen Blutstammzellen von der Dauer und Art der Immunsuppression und den Ergebnissen der virologischen Überwachungsuntersuchungen abhängen. Die späte CMV-Erkrankung nach Blutstammzelltransplantation, insbesondere nach dosisreduzierter Konditionierung und bei verstärkter Immunsuppression wegen drohender Abstoßung eines transplantierten soliden Organs, wird zunehmend häufig beobachtet. Sie erfordern eine Prophylaxe mit intravenösem oder oralem Ganciclovir oder Valganciclovir. Nach längerer Ganciclovirexposition muss mit Ganciclovir-resistenten Viren gerechnet werden [53].

\section{Therapie}

Die Therapie der HSV-Pneumonie besteht in der Gabe von Aciclovir 3-mal 5$10 \mathrm{mg} / \mathrm{kg} /$ Tag über 14-21 Tage. In 2-10\% der Fälle können Aciclovir-resistente Viren isoliert werden [54]. Therapie der Wahl ist in diesen Fällen Foscarnet (3$\mathrm{mal} 60 \mathrm{mg} / \mathrm{kg} / \mathrm{Tag}$ ) [55]. Seltene schwere viszerale Komplikationen der VZV-Infektion werden mit Aciclovir 10-15 mg/ $\mathrm{kg} /$ Tag für etwa 14 Tage behandelt.

Die Therapie der RSV-Pneumonie (Mortalität 6o-80\%) besteht in der Gabe von Ribavirin in Aerosolform $(20 \mathrm{mg} / \mathrm{ml}$ für 18 Stunden/Tag) oder Ribavirin i.v. $25 \mathrm{mg} / \mathrm{kg} /$ Tag als Initialdosis, dann 3-mal $5 \mathrm{mg} / \mathrm{kg} / \mathrm{Tag}$ in Kombination mit Immunglobulinen i.v. 0,2-0,4 g/kg/Tag 2- bis 3-mal pro Woche [40]. Ihre Wirksamkeit ist jedoch nicht hinreichend geprüft. Schwere Verlaufsformen von Adenovirusinfektionen sind selten (bei etwa $1 \%$ aller Transplantierten). In Einzelfällen wurden Ribavirin und Ganciclovir eingesetzt, es gibt jedoch noch keine etablierte Standardtherapie für Adenovirusinfektionen [36]. Eine spezielle Therapie für Parainfluenzavirus bedingte Pneumonien ist derzeit nicht möglich [35].

Therapeutisch wird bei der CMVPneumonie Ganciclovir (2-mal 5 mg/kg/ Tag) meist in Kombination mit hohen
Dosen intravenöser Immunglobuline eingesetzt [56]. Grundsätzlich verlangt die Therapie der CMV-Infektion/Erkrankung mit Ganciclovir, Foscarnet oder Cidofovir eine so genannte „Induktionsphase“, in der hohe Dosen des Virostatikums die Virusreplikation rasch vermindern, und eine Erhaltungstherapie, in der niedrigere Dosen die CMV-Reaktivierung und das Fortschreiten der CMV-Erkrankung verhindern, z. B. initial Ganciclovir $5 \mathrm{mg} / \mathrm{kg}$ alle 12 Stunden für 14 Tage und anschließend $5 \mathrm{mg} / \mathrm{kg} / \mathrm{Tag}$.

Vor der Proteaseinhibitor-basierten „highly active antiretroviral Therapy“ (HAART) konnten CMV-Erkrankungen, z. B. die CMV-Retinitis, bei $85 \%$ der AIDS- oder HIV-infizierten Patienten mit geringer $\mathrm{CD}_{4}$-Zahl beobachtet werden [57]. Unter HAART kann die Erhaltungstherapie nach etwa 6 Monaten bei Anstieg der $\mathrm{CD}_{4}{ }^{+}-\mathrm{T}-$ Zellen abgebrochen werden. Aufgrund der niedrigen Bioverfügbarkeit bei oraler Gabe muss Ganciclovir bei CMV-Retinitis in einer Dosierung von 1,5 g 3-mal/Tag gegeben werden [58]. Eine Alternative ist das seit kurzer Zeit zur Verfügung stehende, oral $\mathrm{zu}$ verabreichende, gut resorbierbare Valganciclovir. Die antivirale Resistenz ist vor allem ein Problem der Langzeitbehandlung.

\section{Toxoplasma-gondii- und Pneu- mocystis-carinii-Infektionen}

Toxoplasma gondii ist ein häufiger Erreger opportunistischer Infektionen. Immunsupprimierte Patienten sollten eine Exposition vermeiden. Prophylaktisch wirksam sind Trimethoprim-Sulfamethoxazol (TMP/SMZ) oder eine Kombinationen aus Pyrimethamin/Leucovorin mit Sulfadiazin oder Dapson. Beide Regime wirken auch gegen Pneumocystis-carinii-Infektionen [59,60].

Pneumocystis carinii ist ein extrazellulärer, im Alveolarraum persistierender, einzelliger Pilz, der bei immunsupprimierten Patienten schwere Pneumonien verursachen kann. Patientengruppen mit ausgeprägter Immunsuppression sollten eine Prophylaxe erhalten. Als Standardprophylaxe gilt TMP/SMZ in der bevorzugten Dosierung von $960 \mathrm{mg} /$ Tag. Alternativ kann TMP/SMZ in einer Dosierung von $480 \mathrm{mg} / \mathrm{Tag}$ oder $960 \mathrm{mg}$ 3-mal/Woche verabreicht werden. Weitere Möglichkeiten bestehen in der prophylaktischen regelmäßigen Pentami-
din-Inhalation oder oralen Applikation von Dapson. Häufig muss die TMP/ SMZ-Prophylaxe aufgrund von Nebenwirkungen beendet werden $[60,61]$. Pulmonale Symptome bei normalem Röntgenbild lassen an eine Pneumocystiscarinii-Pneumonie (PCP) denken. In diesem Fall sind die Untersuchung des induzierten Sputums, evtl. eine BAL und möglicherweise eine TBB angezeigt. Die Pneumocystis-carinii-Pneumonie wird mit hoch dosiertem intravenösem TMP/ SMZ, intravenösem Pentamidin oder mit Clindamycin/Primaquin behandelt. Eine kürzlich veröffentlichte Metaanalyse legt für die „Salvage“-Therapie eine Behandlung mit Clindamycin/Primaquin nahe [62].

\section{Pilzinfektionen}

\section{Inzidenz}

Die Inzidenz von Pilzerkrankungen bei immunsupprimierten Patienten hat in den letzten Jahren zugenommen $[63,64]$. In einer retrospektiven Analyse wurden bei ca. 20-50\% der verstorbenen Patienten mit hämatologischen Neoplasien und bei 19\% der Patienten mit AIDS autoptisch Hinweise für eine Pilzinfektion gefunden [65]. Nach Knochenmark-/ Blutstammzelltransplantation kommt es bei ca. $11-18 \%$ der Patienten zu einer Candidainfektion [66] und bei bis zu 11\% der Patienten zu einer invasiven Aspergillusinfektion [67]. Bei neutropenischen $\mathrm{Pa}$ tienten hängt das Risiko, eine Pilzinfektion zu entwickeln, entscheidend von der Schwere und Dauer der Neutropenie ab [68]. Candida albicans und Aspergillus fumigatus sind für ca. 70-80\% der systemischen Pilzinfektionen bei onkologischen Patienten verantwortlich, während Mucor- und Cryptococcusinfektionen bei diesem Patientenkollektiv nur selten nachgewiesen werden.

Pilzinfektionen nach Organtransplantationen treten mit einer Inzidenz von $5 \%$ (Nierentransplantation), $25 \%$ (Lungentransplantationen) und 40\% (Lebertransplantation) auf, wobei $80 \%$ durch Candida- und Aspergillusspezies hervorgerufen und in den ersten 2 Monaten nach Transplantation manifest werden [69]. Die Candidapneumonie tritt häufig im Rahmen einer Candidasepsis auf. In den USA waren Candida spp. die vierthäufigsten aus Blutkulturen isolierten Organismen. Während Infektionen 
durch Candida albicans abnehmen, scheint die Inzidenz von so genannten Non-Candida-albicans-Infektionen (C. tropicalis, C. glabrata, C. parapsilosis, C. krusei, C. stellatoidea, C. lusitaniae, C. dublinensis) zuzunehmen. Cryptococcusinfektionen entstehen durch Inhalation und treten häufig bei Patienten mit zellulärer Immunsuppression (z. B. HIVInfektion) auf. Bevorzugt befallen werden die Lungen und nach hämatogener Streuung das Zentralnervensystem.

Die Aspergillose manifestiert sich bei immunsupprimierten Patienten am häufigsten als invasive Aspergillusinfektion der Lunge (IPA) [70]. Nach allogener BSZT beträgt die Mortalität bis zu 90\% [71]. Durch die direkte Invasion in das pulmonale Parenchym und Gefäßsystem kommt es zu einer nekrotisierenden Vaskulitis mit konsekutiver hämorrhagischer Infarzierung und bei 10-25\% der Patienten zur extrapulmonalen Dissemination (Gastrointestinaltrakt, Herz, Leber, Milz, Niere, Schilddrüse, ZNS). Neben Aspergillus fumigatus wurden in absteigender Reihenfolge folgende Spezies isoliert: A. flavus, A. terreus und sehr selten $A$. niger, $A$. nidulans, A. versicolor, A. oryzae, A. glaucus.

Bei HIV-infizierten Personen steigt das Risiko einer Pilzinfektion deutlich an, wenn die $\mathrm{CD}_{4}{ }^{+}$-Zellen unter 100-200 Lymphozyten/ $\mu$ l gefallen sind (Candida, Cryptococcus neoformans, Aspergillus fumigatus, Histoplasma capsulatum, Coccidioides immitis, Blastomyces dermatidis) [72]. Candidainfektionen (Soor und Soorösophagitis) sind die häufigsten Pilzinfektionen bei HIV-infizierten Patienten. Candidapneumonien sind eine Rarität. Vor dem Hintergrund einer wirksamen und konsequenten antiretroviralen Therapie werden deutlich weniger Pilzinfektionen beobachtet.

\section{Diagnostik}

Die klinische Symptomatik der invasiven Aspergillusinfektion der Lunge ist in der Frühphase häufig uncharakteristisch (Husten 92\%, Brustschmerzen $76 \%$, Hämoptysen 54\%). Der direkte Nachweis von Aspergillus in Blutkulturen gelingt nur selten, ein histologischer Nachweis durch Biopsien kann wegen der Thrombozytopenie nur selten erbracht werden. Häufig finden sich bei der invasiven Aspergillusinfektion der Lunge röntgenologisch rundlich-fleck-
Übersicht 4

Klassifikation der invasiven

pulmonalen Aspergillose

- Definitive Aspergillose

- Invasive Pilzpneumonie passend zur Aspergillose, die histologisch durch transbronchiale oder offene Lungenbiopsie bewiesen wurde, oder perkutane Aspiration einer Lungenläsion, die entweder ein positives Kulturergebnis für Aspergillusspezies zeigt oder die bei der mikroskopischen Untersuchung eine positive Histologie mit typischen sich verzweigenden Hyphen erbringt.

- Wahrscheinliche Aspergillose

- Vorhandensein von progressiven oder neu aufgetretenen radiologischen Lungeninfiltraten (Röntgen- oder CT-Thorax) und positiver Aspergillusnachweis innerhalb der nächsten 7 Tage an folgenden Stellen:

- eine andere ungewöhnliche Stelle (Gewebe, histologische Diagnose), z. B. Haut oder Nasennebenhöhlen,

- bei bestehender Neutropenie $\left(<1000 \times 10^{9}\right.$ Neutrophile/L) entweder durch nasale Kultur oder Sputumkultur oder Kultur oder zytologische Untersuchung der BAL, falls keine Neutropenie besteht entweder durch Sputumkultur innerhalb von 7 Tagen eines neu aufgetretenen Infiltrats oder Kultur oder zytologische Untersuchung der BAL.

- Bronchoskopie, die eine Ulzeration oder eine Pseudomembranbildung in der Trachea oder den Bronchien zeigt und gleichzeitiger Nachweis von Aspergillusspezies in der BAL oder oberflächliche oder tiefe Invasion der Bronchialmukosa durch histologischen Nachweis von Hyphen passend zu Aspergillusspezies.

CT-Untersuchung des Thorax, die eine Aspergillusinfektion wahrscheinlich macht (,halo"- oder Luftsichelzeichen oder pleurale scharf gewinkelte Läsion oder pleurale Läsion mit Pneumothorax). (Nach Caillot et al., Clin Infect Dis 2001)

förmige bronchopneumonische Infiltrate, die multifokal besonders in der Peripherie lokalisiert sind. Aber auch infarktpneumonische Bilder bis hin zu einem unauffälligen Röntgenbefund werden beobachtet. Frühzeitig sollte bei Patienten mit Verdacht auf eine IPA ein HRCT des Thorax (Übersicht 4) veranlasst werden [73].
Invasive Aspergillusinfektionen manifestieren sich häufig als unscharfe Verschattungen („milchglasartig“), nekrotisierende Bronchopneumonie mit sekundärer Ausbildung von Lungeninfarkten, Abszessen und Höhlenbildungen. Pilzsequestrationen, Einschmelzungen und das so genannte „Halo“-Zeichen werden als LISA („lesions with imaging suggestive of aspergillosis") bezeichnet und haben einen $82-90 \%$ positiv-prädiktiven Wert für eine invasive Aspergillusinfektion der Lunge [74]. Invasive Methoden, vor allem die FOB mit BAL, haben ebenfalls einen festen Stellwert. Die Sensitivität der BAL liegt bei 14-60\% [74]. Bei blutstammzelltransplantierten Patienten ist jedoch die signifikante Komplikationsrate der FOB (o-40\%), bei z.T. nur geringer diagnostischer Aussagekraft (31-89\%), zu berücksichtigen [75].

\section{„Nach Lungentransplantation kann Aspergillus im Respirations- trakt bei bis zu 23\% der Patienten nachgewiesen werden."}

Die eingehende mykologische Diagnostik umfasst die mikroskopische und kulturelle Untersuchung des Bronchiallavageats, welches aussagekräftigere Untersuchungsergebnisse liefert als das Sputum. Der Nachweis von Hefen im Sputum oder in der bronchoalveolären Lavage wirft immer die Frage auf, ob es sich um eine Kontamination oder Kolonisation ohne invasives Wachstum oder um invasiven Befall der Lunge handelt. Die Isolierung von Aspergillus aus der BAL und/oder Sputum bei stammzelltransplantierten Patienten sollte jedoch stets an eine invasive Aspergillose denken lassen. Nach Lungentransplantation kann Aspergillus im Respirationstrakt bis zu 23\% der Patienten nachgewiesen werden, ohne dass dieser Nachweis in jedem Fall mit einer invasiven Aspergillose vergesellschaftet sein muss.

Die Serodiagnostik kann in $2 \mathrm{An}$ sätze unterteilt werden: der Nachweis von Antikörpern und der Nachweis von Pilzantigenen. Die Bestimmung der Serumantikörper ist unzuverlässig, da Antikörper bei Immunsupprimierten häufig zu spät oder gar nicht gebildet werden. Die Nützlichkeit des Nachweises der Antigenämie bei invasiver Candidiasis [„reverse passive latex agglutination“(RPLA)] oder Aspergillose [La- 
tex-Agglutinationstest (Pastorex Aspergillus)] wird durch die rasche Elimination des Candida-Mannans und des Aspergillus-Galaktomannans aus dem Serum begrenzt (geringe Sensitivität). Bei einmaliger Testung resultieren sehr häufig falsch negative Ergebnisse. Der wiederholte Nachweis von Antigen im Urin kann die Sensitivität erhöhen [76]. Kürzlich wurden die Ergebnisse einer prospektiven Studie zum Nachweis von Galactomannan (GM) im Serum (2-mal/ Woche) mit einem ELISA-Assay (Platelia Aspergillus) bei Patienten mit prolongierter Neutropenie veröffentlicht, die eine hohe Sensitivität und Spezifität des Testes nahe legen. Der serologische Nachweis von GM ging einer definitiven Diagnose bei 29 von 30 Patienten um im Median 17 Tage voraus [77]. Für die Kryptokokkose stellt die Bestimmung des Cryptococcus-Antigens im Serum einen hervorragenden Screeningtest dar.

Sensitive Nachweismethoden auf der Basis Aspergillus- und Candida-spezifischer Polymerasekettenreaktion (PCR) werden derzeit entwickelt und hoffentlich zu einer sensitiven und spezifischen Frühdiagnostik invasiver Mykosen führen $[78,79]$.

\section{Prophylaxe}

Eine Pilzprophylaxe scheint sinnvoll für Patienten, deren erwartete Neutropeniedauer $\left(0,1-0,5 \times 10^{9} / \mathrm{L}\right)$ mehr als zwei Wochen beträgt oder die eine schwere Neutropenie $\left(<0,1 \times 10^{9} / \mathrm{L}\right)$ von mehr als einer Woche entwickeln. Patienten, die allogen blutstammzelltransplantiert werden, sollten als Hochrisikopatienten ebenfalls eine Pilzprophylaxe erhalten.

\section{Candida}

Optimale Hygiene inklusive Händewaschen sind von entscheidender Bedeutung [63]. Fluconazol ist erfolgreich zur Prophylaxe von Pilzinfektionen während der Behandlung von akuten Leukämien und im Rahmen der Knochenmarktransplantation eingesetzt worden [66]. Die Zahl disseminierter Candida-albicansund -tropicalis-Infektionen nimmt signifikant ab, jedoch haben Patienten unter Fluconazolprophylaxe ein 7-fach erhöhtes Risiko, eine Infektion mit Fluconazolresistenten Candida-krusei-Hefen zu entwickeln. Zusammenfassend kann festge- stellt werden, dass für allogen stammzelltransplantierte Patienten und Hochrisikopatienten, die sich einer autologen BSZT unterziehen, eine Prophylaxe mit Fluconazol (400 mg/Tag) empfohlen wird [63]. Aspergillusinfektionen werden hierdurch allerdings nicht mit erfasst.

\section{Aspergillus}

Da die meisten Infektionen durch Inhalation von Schimmelpilzkonidien entstehen, ist die Unterbringung von Hochrisikopatienten in "laminar air flow“(LAF-)Räumen mit einer „high-efficiency particulate air"- (HEPA-)Filtration sinnvoll und effektiv [8o]. Niedrig dosiertes i.v.-Amphotericin B (0,1-0,25 mg/ $\mathrm{kg} \mathrm{KG/Tag)} \mathrm{[81]} \mathrm{und} \mathrm{inhalatives} \mathrm{Ampho-}$ tericin B können als Prophylaxe nicht empfohlen werden [82].

Prophylaktisch eingesetztes liposomal verkapseltes Amphotericin B (1 mg/ kg KG/Tag) führte bei Transplantationspatienten zu einer Reduktion der fungalen Kolonisation und einer nicht signifikanten Reduktion bewiesener Pilzinfektionen, aber nicht zu einem Überlebensvorteil [83]. Intravenöses niedrig dosiertes liposomales Amphotericin B (2 mg/ $\mathrm{kg} \mathrm{KG/Tag,3-mal/Woche)} \mathrm{reduzierte} \mathrm{we-}$ der die Zahl der Pilzinfektionen noch die Mortalität. Itraconazol als orale Lösung hat sich als effektiv in der Pilzprophylaxe bei neutropenischen Patienten in 3 Studien bewährt [84, 85]. Wichtig scheinen adäquate Itraconazolspiegel zu sein, die mindestens (250-) $500 \mathrm{ng} / \mathrm{ml}$ betragen sollten. In der Prophylaxe können diese Spiegel nach Applikation der oralen Lösung bei $86-100 \%$ der Patienten erst nach ca. 12 Tagen erreicht werden [84]. Nach intravenöser Gabe werden effektive Spiegel in der Mehrzahl der Fälle (97\%) bereits nach 2 Tagen erreicht [86].

Bezüglich der Dauer der Prophylaxe sollte bei folgenden Patientengruppen eine langfristige Prophylaxe erwogen werden: Patienten unter langfristiger hoch dosierter Steroidtherapie, Patienten nach „HLA-mismatch“-allogener BSZT, Patienten mit einer GvHD, Patienten, die eine hochpotente Kombinationschemotherapie erhalten haben (insbesondere Fludarabin-haltige Kombinationstherapien), Patienten, die eine langfristige Chemotherapie erhalten, und Patienten, die eine myeloablative Chemotherapie nach vorausgegangener invasiver Pilzinfektion erhalten sollen.

\section{Therapie}

\section{Empirische Therapie}

Da bei onkologischen Patienten Pilze autoptisch häufig nachweisbar waren und systemische Pilzinfektionen häufig als unmittelbare Todesursache identifiziert werden konnten, wird seit vielen Jahren das Konzept einer empirischen antimykotischen Therapie bei klinisch vermuteten systemischen Candida- oder Aspergillusinfektionen verfolgt [87]. Dies gilt insbesondere für Hochrisikopatienten, die während der Granulozytopeniephasen Fieber unbekannter Ursache entwickeln und nicht auf eine mehrtägige (72-96 Stunden) Breitspektrumantibiotikatherapie ansprechen [87]. Studien belegen, dass die empirische Gabe von Amphotericin B (o,6-1,omg/kg KG/Tag) zu einer erhöhten Überlebenswahrscheinlichkeit führt. Liposomales Amphotericin B (1-3 mg/kg $\mathrm{KG} / \mathrm{Tag}$ ) ist möglicherweise eine bessere Alternative, da es im Vergleich zu Amphotericin B zu signifikant weniger bewiesenen refraktären („breakthrough“) Pilzinfektionen kommt und bei allogen transplantierten Patienten deutlich weniger neue („,emergent“) Pilzinfektionen auftreten $[88,89]$. Außerdem ist liposomales Amphotericin deutlich besser verträglich, jedoch um ein Vielfaches teurer.

Für granulozytopenische Patienten mit persistierendem Fieber unklarer Ursache, normalem Röntgenthoraxbild, leererAspergillusanamnese,negativen Überwachungskulturen für Aspergillus und geringem Aspergillusinfektionsrisiko konnten Studien eine gleiche Effektivität von intravenösem Amphotericin B (0,5-0,8 mg/kg KG/Tag) und intravenösem Fluconazol (400 mg/Tag) belegen [9o]. Fluconazol führte zu deutlich weniger Nebenwirkungen. Bei Patienten mit Lungeninfiltraten in der febrilen Neutropenie ist jedoch wegen fehlender Aspergilluswirksamkeit von Fluconazol bereits initial konventionelles oder liposomales Amphotericin B zu empfehlen.

In der empirischen antifungalen Therapie bei neutropenischen Patienten scheint Itraconazol mindestens so effektiv wie Amphotericin, führt jedoch $\mathrm{zu}$ deutlich weniger Nebenwirkungen [86].

\section{Therapieempfehlung}

Zur Behandlung der Candidapneumonie wird Amphotericin B (>0,7 mg/kg 
KG/Tag) allein oder in Kombination mit 5-Flucytosin [100(-150) mg/kg KG/Tag] [91] empfohlen. Eine effektive Alternative ist bei ausgeschlossener Resistenz gegenüber Fluconazol (cave: C. krusei und C. glabrata) und zuvor nicht stattgehabter Fluconazolprophylaxe die Behandlung mit dem Triazol Fluconazol [92]. Amphotericin ( $<1,5 \mathrm{mg} / \mathrm{kg} \mathrm{KG/Tag})$ sollte jedoch das Mittel der ersten Wahl bei klinisch instabilen Patienten und Patienten mit einer Organmykose bleiben [64]. Bei der seltenen C.-lusitaniae-Infektion muss mit einer geringeren Empfindlichkeit, evtl. Resistenz gegenüber Amphotericin B, gerechnet werden.

Für die ösophageale Candidiasis bei HIV-positiven Patienten belegen Studienergebnisse die Effektivität von Itraconazol, das ebenso erfolgreich eingesetzt wurde wie Fluconazol [93].

Die Behandlung der invasiven Aspergillose bei immunsupprimierten Patienten stellt weiterhin eine Herausforderung dar. Für die invasive Aspergillusinfektion der Lunge wird Amphotericin B weiterhin in der Behandlung als „Goldstandard“ angesehen, ist jedoch zum Teil mit erheblicher Toxizität verbunden. Amphotericin B wird in Dosen von $1(-1,5)$ $\mathrm{mg} / \mathrm{kg} \mathrm{KG/Tag}$ für die Erstbehandlung empfohlen [22]. Es kann mit einem Ansprechen von ca. 30-50\% gerechnet werden [94]. Für Patienten, die bereits nephrotoxische Medikamente wie Cyclosporin A oder Aminoglykosidantibiotika erhalten, stellt das liposomale Amphotericin B (Ambisome $1-5 \mathrm{mg} / \mathrm{kg} \mathrm{KG/Tag}$ ) eine sinnvolle Alternative für die Erstbehandlung dar [88], wobei es in einer Dosierung von $1 \mathrm{mg} / \mathrm{kg} \mathrm{KG/Tag}$ bis $4 \mathrm{mg} / \mathrm{kg}$ $\mathrm{KG} /$ Tag wohl gleich wirksam ist. Patienten, die unter Behandlung mit Amphotericin $B$ eine Niereninsuffizienz entwickeln, können mit liposomalem Amphotericin B erfolgreich weiterbehandelt werden [95].

Patienten mit invasiver Aspergillose können möglicherweise neben Amphotericin B bei gleicher Effektivität alternativ mit dem Aspergillus-wirksamen Triazol Itraconazol behandelt werden [96, 97, 98]. Eventuell ist die Kombination von Amphotericin B mit Itraconazol bei offensichtlich fehlendem Antagonismus wirksamer. Itraconazol bietet sich auch für die Sekundärprophylaxe nach erfolgreicher Amphotericin-B-Behandlung an [96]. Itraconazol steht als orale (Kapsel und Saft) und intravenöse Darreichungs- form zur Verfügung. Bei der IPA kann mit einem Ansprechen von ca. 32-60\% der Patienten gerechnet werden, wobei Patienten nach allogener Transplantation generell ein schlechteres Ansprechen zeigen als neutropenische Patienten, Patienten nach Organtransplantationen oder AIDSPatienten [96, 99].

Patienten mit LISA (fokale Läsionen, s. oben) sollten zunächst medikamentös behandelt werden. Zeigt sich bei wöchentlich durchgeführten CT-Kontrollen eine Besserung, so sollte die Therapie weiter konservativ erfolgen. Eine vorübergehende Verschlechterung ist trotz Effektivität der Therapie möglich. Sollte diese jedoch fortschreiten, insbesondere wenn die Läsion die Integrität der Pulmonalarterien zu gefährden droht, sollte eine Operation - sofern vertretbar - durchgeführt werden. Über eine chirurgische Entfernung sollte auch vor Durchführung einer allogenen Transplantation nachgedacht werden [100]. Bei Hämoptysen ist je nach Schweregrad die unmittelbare Operation indiziert [74]. Aspergillome in präexistenten und nichtmykotischen Höhlen müssen jedoch von Aspergillomen unterschieden werden, die durch eine invasive Lungenaspergillose nach Einschmelzung und Demarkation entstehen.

Die Behandlung der Cryptococcusinfektion besteht aus einer systemischen Gabe von Amphotericin B in Kombination mit Flucytosin (100-150 mg/kg $\mathrm{KG} / \mathrm{Tag}$ ). Die Kombinationstherapie hat sich der alleinigen Gabe von Amphotericin B als überlegen erwiesen.

\section{Neue antimykotische Medikamente}

Caspofungin gehört $\mathrm{zu}$ einer neuen Klasse antimykotischer Substanzen, die sehr schnell und nicht kompetitiv die Synthese des $\beta-(1,3)$-D-Glucan und damit die Zellwandsynthese der Pilze inhibieren. Es ist das erste in Deutschland zugelassene Echinocandin und zeigt fungizide Wirkung gegen Candidahefen (einschließlich C. krusei und glabrata) und Aspergillusspezies. Bei der invasiven Aspergillose wurde ein Ansprechen von ca. $40 \%$ gefunden. Patienten mit ungenügendem Ansprechen auf die Vortherapie zeigten unter Caspofungin ein Ansprechen von $34 \%$, während das Ansprechen von Patienten, die eine Unverträglichkeit gegenüber anderen Antimykotika zeigten, bei ca. 70\% lag. Caspo- fungin erwies sich auch als hocheffektiv bei oropharyngealer und ösophagealer Candidiasis bei HIV-Patienten [101,102].

Voriconazol, derzeit in klinischer Prüfung, ist ein Triazol der zweiten Generation, welches das Cytochrom-P450abhängige Enzym 14- $\alpha$-Demethylase blockiert und damit die Synthese von Ergosterol hemmt. Es ist als intravenöse und orale (bis zu 96\%ige Bioverfügbarkeit) Darreichungsformen verfügbar. Es hat fungizide Wirkung gegenüber Aspergillusspezies und wirkt fungistatisch gegenüber Candidaspezies (inklusive Candida krusei und glabrata) [103].

Voriconazol ist darüber hinaus gegen Cryptococcus neoformans wirksam. Von besonderem Vorteil sind die therapeutisch wirksamen Liquorspiegel und die nachgewiesene Wirksamkeit bei zerebralen Infektionen. In einer randomisierten Studie wurden 277 Patienten mit invasiver Aspergillose einer Initialtherapie mit Voriconazol oder Amphotericin B zugeführt. Unter Voriconazol wurde ein Ansprechen von ca. 50\% gefunden, das Überleben der Patienten war nach Therapie mit Voriconazol deutlich besser als nach Amphotericin-B-Behandlung. Bei oropharyngealer und ösophagealer Candidiasis ist Voriconazol bei verbessertem Wirkungsspektrum dem Fluconazol äquieffektiv und kann auch bei Fluconazol-resistenten Candidastämmen eingesetzt werden. In einer anderen Studie zum empirischen Einsatz von Voriconazol bei neutropenischen Patienten waren die Ergebnisse mit denen nach Einsatz von liposomalem Amphotericin B vergleichbar, jedoch bezüglich „breakthrough"-Pilzinfektionen und der Toxizität deutlich günstiger [104, 105, 106, 107].

\section{Seltene Pilzpneumonien}

Auch für die bei uns seltener vorkommenden Pilzpneumonien wie Blastomykose, Histoplasmose, Paracoccidioidomykose, Sporotrichose, Mucormykose oder Coccidioidomykose wird eine hochdosierte Amphotericin-B-Therapie empfohlen. Dies gilt ebenso für die pulmonale Kryptokokkosemanifestationen. Invasive Pilzinfektionen können auch durch weniger bekannte Fungi wie Fusarium, Penicillium marneffei, Trichosporon beigelii, Blastoschizomyces capitatus und Malassezia furfur hervorgerufen werden. Diese Infektionen scheinen zuzunehmen. 


\section{Fazit}

Zusammenfassend kann festgestellt werden, dass pulmonale Infektionen bei immunsupprimierten Patienten weiterhin eine Herausforderung für den behandelnden Arzt sind. Für diagnostische und therapeutische Erwägungen sind die Art und Dauer der Immunsuppression von entscheidender Bedeutung. Viele offene Fragen zur optimalen Prophylaxe und Therapie insbesondere viraler und mykotischer Infektionen müssen noch durch große randomisierte Studien beantwortet werden. Eine interdisziplinäre Zusammenarbeit zwischen Internisten, Radiologen, Chirurgen, Mikrobiologen und Virologen ist für ein erfolgreiches Management sehr wünschenswert.

Aktuelle Leitlinien verschiedener Fachgesellschaften sind im Internet unter folgenden Adressen abrufbar: www.dgho-infektionen.de (Deutsche Gesellschaft für Hämatologie und Onkologie), www.idsociety.org (Infectious Diseases Society of America), www.rki.de (Robert Koch-Institut), www.cdc.gov (Centers for Disease Control and Prevention).

\section{Literatur}

1. Takatsuka H, Takemoto Y, Yamada S et al. (2000) Complications after bone marrow transplantation are manifestations of systemic inflammatory response syndrome.

Bone Marrow Transplant 26:419-426

2. Pizzo PA (1999) Fever in immunocompromised patients. N Engl J Med 341:893-900

3. Corey L, Boeckh M (2002) Persistent fever in patients with neutropenia. $\mathrm{N}$ Engl J Med 346:222-224

4. Sing A, Leitritz L, Roggenkamp A et al. (1999) Pulmonary toxoplasmosis in bone marrow transplant recipients: report of two cases and review. Clin Infect Dis 29:429-433

5. Aronchik JM (2000) Pulmonary infections in cancer and bone marrow transplant patients. Sem Roentgenol XXXV:140-151

6. Heussel CP, Kauczor HU, Heussel GE et al. (1999) Pneumonia in febrile neutropenic patients and in bone marrow and blood stem-cell transplant recipients: use of high-resolution computed tomography. J Clin Oncol 17:796-805

7. Hwang SS, Kim HH, Park SH et al. (2000) The value of CT-guided percutaneous needle aspiration in immunocompromised patients with suspected pulmonary infection. Am J Roentgenol 175:235-238
8. Ramila E, Sureda A, Martino R et al. (2000) Bronchoscopy guided by high-resolution computed tomography for the diagnosis of pulmonary infections in patients with hematologic malignancies and normal plain chest X-ray. Haematologica 85:961-966

9. Maitre B, Jaber S, Maggiore SM et al. (2000) Continuous positive airway pressure during fiberoptic bronchoscopy in hypoxemic patients. A randomized double-blind study using a new device. Am J Respir Crit Care Med 162:1063-1067

10. Hohenadel IA, Kiworr M, Genitsariotis R et al. (2001) Role of bronchoalveolar lavage in immunocompromised patients with pneumonia treated with a broad spectrum antibiotic and antifungal regimen. Thorax 56:115-120

11. Whittle AT, Davis M, Johnson PR et al. (1999) The safety and usefulness of routine bronchoscopy before stem cell transplantation and during neutropenia. Bone Marrow Transplant 24:63-67

12. Ninane V (2001) Bronchoscopic invasive diagnostic techniques in the cancer patient. Curr Opin Oncol 13:236-241

13. Maschmeyer $G$ (2001) Pneumonia in febrile neutropenic patients: radiologic diagnosis. Curr Opin Oncol 13:229-235

14. Miller LW, Naftel DC, Bourge RC et al. (1994) Infection after heart transplantation: a multiinstitutional study.J Heart Lung Transplant 13:381-392

15. Frist WH, Loyd JE, Merrill WH et al. (1994) Single lung transplantation: a temporal look at rejection, infection. Am Surg 60:94-102

16. Lossos IS, Breuer R, Or R et al. (1995) Bacterial pneumonia in recipients of bone marrow transplantation. A five-year prospective study. Transplantation 60:672-678

17. Cordonnier C, Bernaudin JF, Bierling P et al. (1986) Pulmonary complications occurring after allogeneic bone marrow transplantation. A study of 130 consecutive transplanted patients. Cancer 58:1047-1054

18. Wade JJ, Rolando N, Hayllar K et al. (1995) Bacterial and fungal infections after liver transplantation: an analysis of 284 patients. Hepatology 21:1328-1336

19. Krowka MJ, Rosenow EC, III, Hoagland HC (1985) Pulmonary complications of bone marrow transplantation. Chest 87:237-246

20. McWhinney $\mathrm{PH}$, Yates $\mathrm{M}$, Prentice $\mathrm{HG}$ et al. (1992) Infection caused by Mycobacterium chelonae: a diagnostic and therapeutic problem in the neutropenic patient. Clin Infect Dis 14:1208-1212

21. Sickles EA, Greene WH, Wiernik PH (1975) Clinical presentation of infection in granulocytopenic patients. Arch Intern Med 135:715-719

22. Hughes WT, Armstrong D, Bodey GP et al. (1997) 1997 guidelines for the use of antimicrobial agents in neutropenic patients with unexplained fever. Infectious Diseases Society of America.Clin Infect Dis 25:551-573
23. Kern W, Kurrle E (1991) Ofloxacin versus trimethoprim-sulfamethoxazole for prevention of infection in patients with acute leukemia and granulocytopenia. Infection 19:73-80

24. Carratala J, Fernandez-Sevilla A, Tubau F et al. (1995) Emergence of quinolone-resistant Escherichia coli bacteremia in neutropenic patients with cancer who have received prophylactic norfloxacin. Clin Infect Dis 20:557-560

25. Kaplan JE, Masur H, Holmes KK et al. (2000) An overview of the 1999 US Public Health Service/Infectious Diseases Society of America guidelines for preventing opportunistic infections. Clin Infect Dis 30 [Suppl 1]: S15-S28

26. Vandercam B, Gerain J, Humblet $Y$ et al. (2000) Meropenem versus ceftazidime as empirical monotherapy for febrile neutropenic cancer patients. Ann Hematol 79:152-157

27. Behre G, Link H, Maschmeyer G et al. (1998) Meropenem monotherapy versus combination therapy with ceftazidime and amikacin for empirical treatment of febrile neutropenic patients. Ann Hematol 76:73-80

28. Shah PM, Heller A, Fuhr HG et al. (1996) Empirical monotherapy with meropenem versus imipenem/cilastatin for febrile episodes in neutropenic patients. Infection 24:480-484

29. Feld R, DePauw B, Berman S et al. (2000) Meropenem versus ceftazidime in the treatment of cancer patients with febrile neutropenia: a randomized, double-blind trial.J Clin Oncol 18:3690-3698

30. Furno P, Bucaneve G, Del Favero A (2002) Monotherapy or aminoglycoside-containing combinations for empirical antibiotic treatment of febrile neutropenic patients: a meta-analysis. Lancet Infect Dis 2:231-242

31. Peacock JE, Herrington DA, Wade JC et al. (2002) Ciprofloxacin plus piperacillin compared with tobramycin plus piperacillin as empirical therapy in febrile neutropenic patients. A randomized, double-blind trial. Ann Intern Med 137:77-87

32. Sanz MA, Lopez J, Lahuerta JJ et al. (2002) Cefepime plus amikacin versus piperacillin-tazobactam plus amikacin for initial antibiotic therapy in haematology patients with febrile neutropenia: results of an open, randomized, multicentre trial. J Antimicrob Chemother 50:79-88

33. Whimbey E, Champlin RE, Couch RB et al. (1996) Community respiratory virus infections among hospitalized adult bone marrow transplant recipients. Clin Infect Dis 22:778-782

34. McCarthy AJ, Kingman HM, Kelly C et al.(1999) The outcome of 26 patients with respiratory syncytial virus infection following allogeneic stem cell transplantation.

Bone Marrow Transplant 24:1315-1322

35. Nichols WG, Corey L, Gooley T et al. (2001) Parainfluenza virus infections after hematopoietic stem cell transplantation: risk factors, response to antiviral therapy, and effect on transplant outcome. Blood 98:573-578 
36. Baldwin A, Kingman H, Darville M et al. (2000) Outcome and clinical course of 100 patients with adenovirus infection following bone marrow transplantation.

Bone Marrow Transplant 26:1333-1338

37. Meyers JD, Flournoy N, Thomas ED (1986) Risk factors for cytomegalovirus infection after human marrow transplantation.J Infect Dis 153:478-488

38. Ljungman P, Aschan J, Lewensohn-Fuchs I et al. (1998) Results of different strategies for reducing cytomegalovirus-associated mortality in allogeneic stem cell transplant recipients. Transplantation 66:1330-1334

39. La Rosa AM, Champlin RE, Mirza N et al. (2001) Adenovirus infections in adult recipients of blood and marrow transplants. Clin Infect Dis 32:871-876

40. Ghosh S, Champlin RE, Englund J et al. (2000) Respiratory syncytial virus upper respiratory tract illnesses in adult blood and marrow transplant recipients: combination therapy with aerosolized ribavirin and intravenous immunoglobulin. Bone Marrow Transplant 25:751-755

41. Buchbinder S, Elmaagacli AH, Schaefer UW, Roggendorf M (2000) Human herpesvirus 6 is an important pathogen in infectious lung disease after allogeneic bone marrow transplantation. Bone Marrow Transplant 26:639-644

42. Tamm M, Traenkle P, Grilli B et al. (2001) Pulmonary cytomegalovirus infection in immunocompromised patients. Chest 119:838-843

43. Saral R, Burns WH, Laskin OL et al. (1981) Acyclovir prophylaxis of herpes-simplex-virus infections. N Engl J Med 305:63-67

44. Masaoka T, Hiraoka A, Teshima H, Tominaga N (1993) Varicella-zoster virus infection in immunocompromised patients.J Med Virol Suppl 1:82-84

45. Bowden RA, Slichter SJ, Sayers M et al. (1995) A comparison of filtered leukocyte-reduced and cytomegalovirus (CMV) seronegative blood products for the prevention of transfusion-associated CMV infection after marrow transplant. Blood 86:3598-3603

46. Boeckh M, Gooley TA, Myerson D et al. (1996) Cytomegalovirus pp65 antigenemia-guided early treatment with ganciclovir versus ganciclovir at engraftment after allogeneic marrow transplantation: a randomized double-blind study. Blood 88:4063-4071

47. Goodrich JM, Bowden RA, Fisher L et al. (1993) Ganciclovir prophylaxis to prevent cytomegalovirus disease after allogeneic marrow transplant. Ann Intern Med 118:173-178

48. Boeckh M, Stevens-Ayers T, Bowden RA (1996) Cytomegalovirus pp65 antigenemia after autologous marrow and peripheral blood stem cell transplantation.J Infect Dis 174:907-912

49. Gleaves CA, Smith TF, Shuster EA, Pearson GR (1985) Comparison of standard tube and shell vial cell culture techniques for the detection of cytomegalovirus in clinical specimens. J Clin Microbiol 21:217-221
50. Schmidt GM, Horak DA, Niland JC et al. (1991) A randomized, controlled trial of prophylactic ganciclovir for cytomegalovirus pulmonary infection in recipients of allogeneic bone marrow transplants. N Engl J Med 324:1005-1011

51. Limaye $A P$, Huang $M L$, Leisenring $W$ et al. (2001) Cytomegalovirus (CMV) DNA load in plasma for the diagnosis of CMV disease before engraftment in hematopoietic stem-cell transplant recipients. J Infect Dis 183:377-382

52. Zaia JA (2002) Prevention and management of CMV-related problems after hematopoetic stem cell transplantation.

Bone Marrow Transplant 29:633-638

53. Limaye AP, Corey L, Koelle DM et al. (2000) Emergence of ganciclovir-resistant cytomegalovirus disease among recipients of solidorgan transplants. Lancet 356:645-649

54. Ljungman P, Ellis MN, Hackman RC et al. (1990) Acyclovir-resistant herpes simplex virus causing pneumonia after marrow transplantation.J Infect Dis 162:244-248

55. Verdonck LF, Cornelissen JJ, Smit J et al. (1993) Successful foscarnet therapy for acyclovirresistant mucocutaneous infection with herpes simplex virus in a recipient of allogeneic BMT. Bone Marrow Transplant 11:177-179

56. Ljungman $P$, Engelhard D, Link $H$ et al. (1992) Treatment of interstitial pneumonitis due to cytomegalovirus with ganciclovir and intravenous immune globulin: experience of European Bone Marrow Transplant Group. Clin Infect Dis 14:831-835

57. Jacobson MA, Zegans M, Pavan PR et al. (1997) Cytomegalovirus retinitis after initiation of highly active antiretroviral therapy. Lancet 349:1443-1445

58. Martin DF, Kuppermann BD, Wolitz RA et al. (1999) Oral ganciclovir for patients with cytomegalovirus retinitis treated with a ganciclovir implant. Roche Ganciclovir Study Group. N Engl J Med 340:1063-1070

59. USPHS/IDSA Prevention of Opportunistic Infections Working Group (2000) 1999 USPHS/IDSA guidelines for the prevention of opportunistic infections in persons infected with human immunodeficiency virus. Clin Infect Dis 30:S29-S65

60. Robert Koch-Institut (2001) Diskussionsentwurf zur Aktualisierung der deutsch-österreichischen Richtlinie zur antiretroviralen Therapie der HIV-Infektion. http://www.rki.de

61. Fishman JA (2001) Prevention of infection caused by Pneumocystis carinii in transplant recipients. Clin Infect Dis 33:1397-1405

62. Smego RA Jr, Nagar S, Maloba B, Popara M (2001) A meta-analysis of salvage therapy for Pneumocystis carinii pneumonia. Arch Intern Med 161:1529-1533

63. Edwards JE Jr, Bodey GP, Bowden RA et al. (1997) International Conference for the Development of a Consensus on the Management and Prevention of Severe Candidal Infections. Clin Infect Dis 25:43-59
64. Denning DW, Evans EG, Kibbler CC et al. (1997) Guidelines for the investigation of invasive fungal infections in haematological malignancy and solid organ transplantation.

British Society for Medical Mycology. Eur J Clin Microbiol Infect Dis 16:424-436

65. Bodey G, Bueltmann B, Duguid W et al. (1992) Fungal infections in cancer patients: an international autopsy survey. Eur J Clin Microbiol Infect Dis 11:99-109

66. Slavin MA, Osborne B, Adams R et al. (1995) Efficacy and safety of fluconazole prophylaxis for fungal infections after marrow transplantation - a prospective, randomized, double-blind study.J Infect Dis 171:1545-1552

67. Wald A, Leisenring W, van Burik JA, Bowden RA (1997) Epidemiology of Aspergillus infections in a large cohort of patients undergoing bone marrow transplantation.J Infect Dis 175:1459-1466

68. Gerson SL, Talbot GH, Hurwitz $S$ et al. (1984) Prolonged granulocytopenia: the major risk factor for invasive pulmonary aspergillosis in patients with acute leukemia. Ann Intern Med 100:345-351

69. Paya CV (1993) Fungal infections in solidorgan transplantation. Clin Infect Dis 16:677-688

70. Fisher BD, Armstrong D, Yu B, Gold JW (1981) Invasive aspergillosis. Progress in early diagnosis and treatment. Am J Med 71:571-577

71. Pannuti CS, Gingrich RD, Pfaller MA, Wenzel RP (1991) Nosocomial pneumonia in adult patients undergoing bone marrow transplantation: a 9-year study.J Clin Oncol 9:77-84

72. Dichter JR, Levine SJ, Shelhamer JH (1993) Approach to the immunocompromised host with pulmonary symptoms. Hematol Oncol Clin North Am 7:887-912

73. Caillot D, Couaillier JF, Bernard A et al. (2001) Increasing volume and changing characteristics of invasive pulmonary aspergillosis on sequential thoracic computed tomography scans in patients with neutropenia.J Clin Oncol 19:253-259

74. Yeghen T, Kibbler CC, Prentice HG et al. (2000) Management of invasive pulmonary aspergillosis in hematology patients: a review of 87 consecutive cases at a single institution. Clin Infect Dis 31:859-868

75. White P, Bonacum JT, Miller CB (1997) Utility of fiberoptic bronchoscopy in bone marrow transplant patients. Bone Marrow Transplant 20:681-687

76. de Repentigny L (1992) Serodiagnosis of candidiasis, aspergillosis, and cryptococcosis. Clin Infect Dis 14 [Suppl 1]:S11-S22

77. Maertens J, Verhaegen J, Lagrou K et al. (2001) Screening for circulating galactomannan as a noninvasive diagnostic tool for invasive aspergillosis in prolonged neutropenic patients and stem cell transplantation recipients: a prospective validation. Blood 97:1604-1610

78. Hashimoto A, Yamakami Y, Karashima R et al. (1998) Evaluation of new method for diagnosis of opportunistic fungal infection. Nippon Ishinkin Gakkai Zasshi 39:187-192 
79. Morace G, Pagano L, Sanguinetti M et al. (1999) PCR-restriction enzyme analysis for detection of Candida DNA in blood from febrile patients with hematological malignancies. J Clin Microbiol 37:1871-1875

80. Caillot D, Casasnovas O, Bernard A et al. (1997) Improved management of invasive pulmonary aspergillosis in neutropenic patients using early thoracic computed tomographic scan and surgery.J Clin Oncol 15:139-147

81. Perfect JR, Klotman ME, Gilbert CC et al. (1992) Prophylactic intravenous amphotericin B in neutropenic autologous bone marrow transplant recipients.J Infect Dis 165:891-897

82. Schwartz S, Behre G, Heinemann V et al. (1999) Aerosolized amphotericin B inhalations as prophylaxis of invasive aspergillus infections during prolonged neutropenia: results of a prospective randomized multicenter trial. Blood 93:3654-3661

83. Tollemar J, Ringden O, Andersson S et al. (1993) Randomized double-blind study of liposomal amphotericin B (Ambisome) prophylaxis of invasive fungal infections in bone marrow transplant recipients. Bone Marrow Transplant 12:577-582

84. Menichetti F, Del Favero A, Martino P et al. (1999) Itraconazole oral solution as prophylaxis for fungal infections in neutropenic patients with hematologic malignancies: a randomized, placebo-controlled, doubleblind, multicenter trial. GIMEMA Infection Program. Gruppo Italiano Malattie Ematologiche dell' Adulto. Clin Infect Dis 28:250-255

85. Morgenstern GR, Prentice AG, Prentice HG et al. (1999) A randomized controlled trial of itraconazole versus fluconazole for the prevention of fungal infections in patients with haematological malignancies.U.K. Multicentre Antifungal Prophylaxis Study Group. Br J Haematol 105:901-911

86. Boogaerts M, Winston DJ, Bow EJ et al. (2001) Intravenous and oral itraconazole versus intravenous amphotericin $B$ deoxycholate as empirical antifungal therapy for persistent fever in neutropenic patients with cancer who are receiving broad-spectrum antibacterial therapy. A randomized, controlled trial. Ann Intern Med 135:412-422

87. Link H, Blumenstengel K, Bohme A et al. (1999) Antimicrobial therapy for fever of unknown origin in neutropenia. Standard recommendations of the Work Group of Infections in Hematology and Oncology of the German Association of Hematology and Oncology. Dtsch Med Wochenschr 124 [Suppl 1]:S3-S8
88. Walsh TJ, Finberg RW, Arndt C et al. (1999) Liposomal amphotericin B for empirical therapy in patients with persistent fever and neutropenia. National Institute of Allergy and Infectious Diseases Mycoses Study Group. N Engl J Med 340:764-771

89. Kruger W, Stockschlader M, Sobottka I et al. (1997) Antimycotic therapy with liposomal amphotericin-B for patients undergoing bone marrow or peripheral blood stem cell transplantation. Leuk Lymphoma 24:491-499

90. Winston DJ, Hathorn JW, Schuster MG et al. (2000) A multicenter, randomized trial of fluconazole versus amphotericin $B$ for empiric antifungal therapy of febrile neutropenic patients with cancer. Am J Med 108:282-289

91. Verweij PE, Donnelly JP, Kullberg BJ et al. (1994) Amphotericin B versus amphotericin B plus 5-flucytosine: poor results in the treatment of proven systemic mycoses in neutropenic patients. Infection 22:81-85

92. Anaissie EJ, Darouiche RO, Abi-Said D et al. (1996) Management of invasive candidal infections: results of a prospective, randomized, multicenter study of fluconazole versus amphotericin B and review of the literature. Clin Infect Dis 23:964-972

93. Wilcox CM, Darouiche RO, Laine L et al. (1997) A randomized, double-blind comparison of itraconazole oral solution and fluconazole tablets in the treatment of esophageal candidiasis. J Infect Dis 176:227-232

94. Harari S (1999) Current strategies in the treatment of invasive Aspergillus infections in immunocompromised patients. Drugs 58:621-631

95. Ellis M, Spence D, de Pauw B et al. (1998) An EORTC international multicenter randomized trial (EORTC number 19923) comparing two dosages of liposomal amphotericin B for treatment of invasive aspergillosis. Clin Infect Dis 27:1406-1412

96. Denning DW, Lee JY, Hostetler JS et al. (1994) NIAID Mycoses Study Group Multicenter Trial of Oral Itraconazole Therapy for Invasive Aspergillosis. Am J Med 97:135-144

97. Denning DW, Marinus A, Cohen J et al. (1998) An EORTC multicentre prospective survey of invasive aspergillosis in haematological patients: diagnosis and therapeutic outcome. EORTC Invasive Fungal Infections Cooperative Group.J Infect 37:173-180

98. Stevens DA, Lee JY (1997) Analysis of compassionate use itraconazole therapy for invasive aspergillosis by the NIAID Mycoses Study Group criteria. Arch Intern Med 157:1857-1862

99. Caillot D, Bassaris H, McGeer A et al. (2001) Intravenous itraconazole followed by oral itraconazole in the treatment of invasive pulmonary aspergillosis in patients with hematologic malignancies, chronic granulomatous disease, or AIDS.Clin Infect Dis 33:e83-e90
100. Reichenberger F, Habicht J, Kaim A et al. (1998) Lung resection for invasive pulmonary aspergillosis in neutropenic patients with hematologic diseases. Am J Respir Crit Care Med 158:885-890

101. Villanueva A, Arathoon EG, Gotuzzo E et al. (2001) A randomized double-blind study of caspofungin versus amphotericin for the treatment of candidal esophagitis. Clin Infect Dis 33:1529-1535

102. Arathoon EG, Gotuzzo E, Noriega LM et al. (2002) Randomized, double-blind, multicenter study of caspofungin versus amphotericin $B$ for treatment of oropharyngeal and esophageal candidiases. Antimicrob Agents Chemother 46:451-457

103. Espinel-Ingroff A, Boyle K, Sheehan DJ (2001) In vitro antifungal activities of voriconazole and reference agents as determined by NCCLS methods: review of the literature. Mycopathologia 150:101-115

104. Hegener P, Troke PF, Fatkenheuer G et al. (1998) Treatment of fluconazole-resistant candidiasis with voriconazole in patients with AIDS. AIDS 12:2227-2228

105. Ally R, Schurmann D, Kreisel W et al. (2001) A randomized, double-blind, double-dummy, multicenter trial of voriconazole and fluconazole in the treatment of esophageal candidiasis in immunocompromised patients. Clin Infect Dis 33:1447-1454

106. Herbrecht R, Denning DW, Patterson TF et al. (2002) Voriconazole versus amphotericin B for primary therapy of invasive aspergillosis. N Engl J Med 347:408-415

107. Walsh TJ, Pappas P, Winston DJ et al. (2002) Voriconazole compared with liposomal amphotericin B for empirical antifungal therapy in patients with neutropenia and persistent fever. N Engl J Med 346:225-234 